\title{
Nociones y prácticas evaluativas basadas en el enfoque por competencias implementado en los Colegios Técnicos Profesionales de Costa Rica
}

Notions and evaluation practices based on the approach for competences implemented in the Professional Technical Colleges of Costa Rica

\section{Volumen 20, Número 2 \\ Mayo - Agosto \\ pp. 1-36}

Silvia Camacho Calvo

\section{Citar este documento según modelo APA}

Corrales Huenul, Angélica., Arriagada Valenzuela, Eduardo y Soto Peranchiguay, Sergio. (2020). Percepciones de estudiantes sobre los programas de orientación en la provincia de Concepción, Chile. Revista Actualidades Investigativas en Educación, 20(2), 1-36. Doi. 10.15517/aie.v20i2.41650 


\title{
Nociones y prácticas evaluativas basadas en el enfoque por competencias implementado en los Colegios Técnicos Profesionales de Costa Rica
}

\author{
Notions and evaluation practices based on the approach for competences implemented in the
} Professional Technical Colleges of Costa Rica

\section{Silvia Camacho Calvo ${ }^{1}$}

\begin{abstract}
Resumen: El análisis de las modalidades educativas por competencias crea una nueva área de investigación, ya que el tema en Cosa Rica ha sido poco abordado. La presente exploración teórico-metodológica está orientada hacia el análisis y la reflexión en torno a los procesos de enseñanza y aprendizaje, y a las nociones y prácticas evaluativas en la implementación del enfoque basado en competencias en los Colegios Técnico Profesionales (CTPs) del Ministerio de Educación Pública (MEP) en Costa Rica. La investigación inicia con un breve análisis crítico sobre las nociones, la construcción del currículo y las prácticas evaluativas bajo los enfoques basados en competencias. Posteriormente, expone los enfoques por competencias generados en el contexto costarricense bajo la modalidad de Educación basada en Normas de Competencia Laboral (EBNC) planteados por Ávila y López, enfoque implementado por el MEP. Para responder a la pregunta de investigación, se construyó una narrativa fundamentada en la hermenéutica de Paul Ricoeur, a partir de este método se realizó el análisis crítico de los relatos teóricos de docentes y de estudiantes sobre las nociones de competencia y las prácticas evaluativas en la EBNC. La investigación se realizó entre el 2015 y 2016. Como propósito, se estableció poner en perspectiva la necesidad de una educación que integre los diferentes aspectos del conocimiento, y que trascienda el énfasis de las habilidades laborales, hacia una educación que permita desarrollar el conocimiento de cómo vivir en el mundo como ciudadano activo. Y donde, además, se reconozca la diversidad como una construcción de significado de las diferentes cosmovisiones, en el sentido de los horizontes de interpretación propuestos por los hermeneutas, es decir, para dar sentido como ser humanos a las experiencias diarias de los actores en el sistema educativo dentro los procesos de enseñanza y aprendizaje.
\end{abstract}

Palabras clave: educación técnica, educación profesional, enfoque por competencias.

\begin{abstract}
The analysis on the educational modalities by competences creates a research area, the present theoretical - methodological exploration is oriented towards the analysis and reflection around the processes of teaching and learning, notions and evaluative practices in the implementation of the competency-based approach in Professional and Technical High Schools in Costa Rica. The research begins with a brief critical analysis on the notions, the curriculum and the evaluative practices under the competency-based approaches, to then contrast them with those generated in the Costa Rican context under the modality of the Education based on Labor Competency Standards (EBNC), implemented by the Ministry of Public Education of Costa Rica. To answer the research question a narrative was constructed, these includes the critical analysis of the theoretical, teachers and student discourses about the notions of competence and the evaluation practices in the EBNC, the analysis took place between 2015 and 2016. The aim was to put in perspective the need for an education that integrates the different aspects of knowledge and that transcends the emphasis of the labor skills towards an education that allows to develop the knowledge of how to live in the world as an active citizen, and where, in addition, diversity is recognized as a construction of significance of different worldviews, in the sense of interpretation horizons proposed by the hermeneuts, that is, to give meaning as a human being of the daily experiences of the actors in the educational system within the learning processes.
\end{abstract}

Key Words: technical education, professional education, competence approach.

\footnotetext{
${ }_{1}^{1}$ Profesora e investigadora en la Universidad de Costa Rica (UCR), en la Licenciatura de Administración de la Educación No Formal y en el Instituto de Investigación en Educación, Costa Rica. ORCID https://orcid.org/0000-0002-7847-2847
}

Dirección electróica: silvia.camachocalvo@ucr.ac.cr

Artículo recibido: 30 de octubre, 2019

Enviado a corrección: 2 de marzo, 2020

Aprobado: 20 de abril, 2020 


\section{Introducción ${ }^{2}$}

La Educación en general es un tema que concierne al Estado, y al ser un proyecto país se articula a asuntos políticos, económicos y sociales, aspectos que la revisten de una complejidad característica de las sociedades posmodernas, en donde la educación tiende a relacionarse con la visión de desarrollo de un país, lo que crea un panorama complejo. Las políticas educativas, por lo general, adoptan diferentes enfoques y modelos educativos, poniendo énfasis, sobre todo, en la pedagogía y en la didáctica, las cuales producen rutas educativas que, a su vez, se convierten en los medios por los que diferentes personas y grupos poblacionales logran una movilidad social y, por tanto, un desarrollo económico.

En el ámbito mundial, desde hace alrededor de treinta años, se han dado cambios estructurales importantes impulsados desde el ámbito económico, como lo han sido la globalización y la mercantilización. Asimismo, en el ámbito social se han desarrollado e incorporado las tecnologías de la información y comunicación (TIC), las cuales han gestado la "sociedad de la información". Estos cambios han transformado la vida de los seres humanos en su cotidianidad, y por tanto, las formas de convivir en todas las sociedades. En el caso de Costa Rica, la apertura comercial hacia mercados globales ha tenido como resultado un incremento en el sector servicios, esto, vinculado a la utilización de la tecnología, generó un crecimiento importante desde la década de los años ochenta (Programa Estado de La Nación, 2010).

Por tanto, el proyecto educativo de un país se convierte en un eje clave de reflexiones sobre su implementación y sus modalidades, en el ámbito nacional e internacional, puesto que impulsa o facilita que los cambios estructurales se den al ritmo que pretenden las sociedades postindustriales. Personas formadas que ingresan a los mercados laborales, capaces de asumir los requerimientos cambiantes de las economías locales, a los ritmos deseados por las economías globales, se convierte en un tema central del papel de la educación, corriendo el riesgo de caer en un papel instrumental de la educación, en donde solamente responda a las dinámicas sociales y políticas.

Se suma a este tema:

(...) la complejidad de por sí inherente a la educación, ya que al mirarla se está observando al ser humano en su inteligibilidad, como sujeto universal o individual, a la escuela como fenómeno social, al Estado, la sociedad, la cultura, la formación, por

2 El presente artículo es producto de la investigación realizada como tesis de la Maestría Académica en Educación con énfasis en Evaluación Educativa, la cual fue defendida en junio del 2017. 
tanto, su estudio es una tarea ardua y "(...) con el surgimiento de los organismos internacionales económicos y sociales recupera fuerza la idea de educación y desarrollo desde la perspectiva de los países desarrollados y subdesarrollados." (Maldonado, 2006, p. 5); vista desde esta óptica, la educación es un camino para construir un modelo social del futuro, en tanto es proyecto educativo. La visión hacia lo individual se deja de lado para encaminar un proyecto político desde lo educativo, que genere impacto en la colectividad social, logrando trascender su ligamen con las necesidades del mercado. (Camacho, 2017, p. 3)

Desde estas reflexiones, y mirando la situación económica costarricense respecto al incremento en el desarrollo de las actividades en el sector servicios, en lo cual, han influido los avances logrados en materia educativa (cobertura y diversidad), lo que ha ido convirtiendo a Costa Rica en una ventaja comparativa respecto a la región, debido a sus inversiones en calidad de la educación.

Así, el gobierno ha instalado como un tema central de sus programas y de la política pública, la educación, desarrollando nuevas modalidades educativas que respondan a las necesidades de formación de las personas y de los mercados económicos cambiantes. En donde, la juventud logre desarrollar las competencias para su oportuna incorporación a los mercados laborales efectivamente, entre estas: iniciativa, creatividad, capacidad de emprendimiento y liderazgo, fluidez tecnológica, pautas de relacionamiento y cooperación, manejo de idiomas, razonamiento lógico, capacidad de análisis e interpretación de información diversa, entre otras (Ávila y López, 2001).

Lo anterior presenta un desafío para Costa Rica, puesto que debe dar respuesta al problema concreto de que una gran cantidad de personas jóvenes no han logrado desarrollar los conocimientos, habilidades y actitudes necesarias para trabajar en empresas 0 instituciones que demandan personas trabajadores con fluidez tecnológica y competencias.

Como respuesta a este dilema, el sistema educativo plantea como opción la educación técnico-profesional, de la cual se pueden establecer los antecedentes en la existencia de la Escuela de Artes y Oficios a principios del siglo XX. Esta fue fundada por un grupo de religiosos salesianos y se convirtió en precedente del Colegio Vocacional de Artes y Oficios (COVAO), la experiencia generada por ambos fungió como fundamento para la formulación del Decreto de 1943, con el cual se crea como institución oficial la Escuela Técnica Industrial en Desamparados, en San José (Mainieri, 2009). Esta opción educativa cuenta con el 
respaldo legal del 25 de septiembre de 1957 y del 22 de noviembre de 1958 en la Ley Fundamental de la Educación, la cual plantea que:

La enseñanza técnica se ofrecerá a quienes desearen hacer carreras de naturaleza vocacional o profesional de grado medio; para ingresar a las cuales se requiere haber terminado la escuela primaria o una parte de la secundaria. La duración de dichas carreras y los respectivos planes de estudio serán establecidos por el Consejo Superior de Educación, de acuerdo con las necesidades del país y con las características peculiares de las profesiones u oficios; y le ofrecerá, además de la Enseñanza Técnica, programas especiales de aprendizaje. (Madriz, 1998, p. 8)

En un principio, esta modalidad educativa se llamó educación vocacional, sin embargo, con la publicación de la Política Educativa hacia El Siglo XXI, se convierte en la Educación Técnica Profesional (ETP). La cual, incrementa progresivamente la cantidad de instituciones que la imparten, por ejemplo para 1997, existían setenta y siete colegios técnicos profesionales, y para 2012, ciento diez colegios y cuarenta secciones nocturnas (Madriz, 1998). Madriz (1998) plantea que la tarea de la educación técnica es:

(...) ofrecer una formación general integral, humanística y tecnológica, que capacite a sus graduados para continuar estudios superiores y que, a la vez, les ofrezca elementos suficientes en su formación técnica que los faculte a desempeñarse en el mercado laboral en una de tres modalidades: agropecuaria, industrial o comercial y de servicios (p. 19).

A nivel curricular, en 1992, se realizaron cambios en las mallas de los programas de estudio, en estos se apostó por los "talleres", los cuales fueron definidos como la posibilidad de relacionar teoría y práctica para cada especialidad. En ese momento se tuvo como desafío primordial la orientación que se le debió dar al docente para que logrará trascender de las actividades de aula a las actividades del taller, la finca o de espacios laborales concretos, incluyendo el conocimiento sobre el uso de las tecnologías en cada especialidad.

El 30 de noviembre de 1995 se aprueba por el Consejo Superior de Educación una nueva propuesta curricular, esta contempla la elaboración de treinta y siete programas de estudio de diversas especialidades técnicas, con una estructura en cuatro áreas: salud ocupacional, gestión empresarial, informática y áreas tecnológicas específicas. 
En el 2006, la Dirección de Educación Técnica y Capacidades Emprendedoras (DETCE) del MEP, área que gestiona los CTPs, implementó la EBNC, lo que implicó que se reformularan las mallas curriculares de las diversas especialidades técnicas con el fin de que estas cumplieran con los requisitos según los estándares del aprendizaje por competencias (Ávila y López, 2001).

La investigación surge desde el interés que nace por parte de la investigadora, al intercambiar con las personas docentes de los CTPs, sobre sus prácticas profesionales, sus vivencias en el aula, sus aproximaciones conceptuales a las competencias, así como sus dudas y preocupaciones respecto a la EBNC y los desafíos que se plantean en el área de la evaluación de los aprendizajes, por consiguiente, desde estos procesos de mirada crítica y escucha activa es que se esboza la pregunta de investigación, ya que las diferentes situaciones relatadas por el profesorado permitieron, que la investigadora, fuera acercándose a sus vivencias y cotidianidades en la implementación del enfoque por competencias. Se planteó como pregunta eje de la investigación: ¿Qué características presentan los aprendizajes y las prácticas evaluativas ${ }^{3}$ en la implementación del enfoque por competencias en la educación técnica costarricense?

El método de investigación permitió la construcción de diversos relatos que posibilitaron contar, desde diversas perspectivas y saberes situados, con una mirada panorámica de la temática. La integración de estos posibilitó la construcción de una narrativa, es decir, de una argumentación crítica de las diversas realidades desde los actores (personas docentes, personas estudiantes, el currículo, el marco epistemológico), las perspectivas de estos fueron rescatadas por la investigadora, y analizada desde las subjetividades de los relatos y desde la construcción de las nociones en torno a estas.

\section{Referentes teóricos: Los relatos teóricos}

Tal como se mencionó anteriormente, al versar la investigación sobre las nociones del profesorado y del estudiantado sobre los procesos de enseñanza y aprendizaje, y las prácticas evaluativas asociadas a la implementación de la EBNC en Colegios Técnico Profesionales, por medio de los cuales se ejecuta la modalidad de la ETP del MEP. La cual, se comprende como aquella que está vinculada al mundo del trabajo, y da respuestas específicas a las necesidades de este. Para la investigación se establecieron como

\footnotetext{
${ }^{3}$ Se entiende por prácticas evaluativas: Actividades que realiza el o la docente para valorar el nivel de desarrollo de las competencias y tomar decisiones pertinentes para el logro de los aprendizajes.
} 
categorías de análisis: la noción por competencias en diferentes enfoques y la EBNC, y los planteamientos teóricos asociadas a las prácticas evaluativas dentro de estas.

\subsection{La noción "competencias"}

Escudero (2009) plantea que las competencias aparecieron en las universidades europeas de forma inadvertida a través de los Libros Blancos, ${ }^{4}$ ya que las Instituciones de Educación Superior (IES) no las plantearon como meta dentro de su planificación curricular, y sin mayor crítica se fueron instalando en los programas de estudio. Además, según el autor, el término competencia se presta a confusión por ser difuso, carece de un marco teórico sólido que oriente la formulación de programas o planes de estudio por competencias para los diversos niveles de la formación, prosigue afirmando, que con estas carencias es que los currículos por competencias han tenido que lidiar, creando diferentes formas de planificación curricular en las distintas titulaciones.

De igual manera, Díaz-Barriga (2011) afirma que los diferentes enfoques por competencias han sido diseñados en el seno de diversas escuelas de pensamiento que han orientado de formas distintas cómo se articula pedagogía, currículo y didáctica, a pesar de que no se ha elaborado una explicación consensuada, clara, articulada y suficiente sobre qué es una competencia. Lo que ha dado como resultado que ningún programa por competencias tenga la misma estructura.

Dentro de estas escuelas de pensamiento se pueden reconocer algunas corrientes, sin embargo, dos de estas se consideran precursoras: la de corte conductual y la de corte sistémica. La primera, por lo general, se relaciona con lo laboral y la segunda se enfoca en lo cognitivo.

Díaz-Barriga (2011) reconoce que no se tiene claro cómo se debe construir un esquema para el planeamiento curricular por competencias, que permita plantear de forma correcta las estrategias o actividades de aula y sus prácticas evaluativas correspondientes. Así, afirma que en la diversidad de propuestas, en tanto construcción curricular, subyace un caos de información; por tanto, cuando se trabaja bajo este enfoque es necesario clarificar desde qué corriente de pensamiento se está trabajando.

\footnotetext{
${ }^{4}$ Los Libros Blancos fueron elaborados por diversas comisiones creadas por la ANECA, estos establecen las directrices para las reformas educativas de las titulaciones (http://www.aneca.es/Documentos-ypublicaciones/Otros-documentos-de-interes/Libros-Blancos).
} 
Es importante establecer que las competencias están condicionadas por factores lingüísticos, sociales, históricos y culturales que las sitúan en un contexto, y que su función primordial es la integración de los saberes y su consecuente actuación ante situaciones que requieren su movilización en la vida cotidiana de cada persona. Las competencias integran los saberes planteados por Delors (1996) respecto a los cuatro "pilares del conocimiento": saber, saber hacer, saber ser y saber estar. Por tanto, las competencias integran: a) el qué (contenidos o formas de saber), el cómo (métodos o formas de hacer) y el para qué (capacidades, actitudes y valores).

Además, Delors (1996) plantea que todo sistema educativo estructurado debe abordar con igual atención los saberes, con la finalidad de que: “(...) la educación sea para el ser humano, en su calidad de persona y de miembro de la sociedad, una experiencia global y que dura toda la vida en los planos cognoscitivos y práctico." (p. 96). Es fundamental tener este postulado en cuenta cuando se investigan las competencias, porque algunas escuelas de pensamiento, sobre todo las relacionadas con lo laboral, desdibujan la integración de los cuatro saberes, poniendo énfasis en alguno de ellos.

En el aula, la integración de los saberes recobra especial importancia porque las actividades didácticas y su mediación pedagógica lograrían que el estudiantado desarrolle las competencias. Así, Zabala y Arnau (2009) establecen que se puede afirmar que una persona es competente cuando, ante una situación que debe resolver actúa logrando movilizar de forma integral y eficaz los saberes, en consecuencia, el desarrollo de una competencia presupone la progresión en la integración de los desempeños. En resumen, no es una cuestión de que una persona tenga o no tenga una competencia, sino que se logra en grados, progresando en estos hasta desarrollarla. De esto se desprende que a la hora de evaluar una competencia no se puede realizar en términos de todo o nada, sino en desarrollo continuo o espectro de actuación.

Por consiguiente, Escudero (2009) caracteriza una competencia como:

(...) descripciones de los aprendizajes de los estudiantes incluyendo múltiples ingredientes (recursos cognitivos de diversa naturaleza, personales, sociales, valores), implican la capacidad de movilizarlos e integrarlos, en orden a definir y responder adecuadamente a situaciones o problemas complejos en contextos relativamente bien definidos, tomando en consideración criterios sociales y éticos establecidos.” (p. 72) 
Desde un punto de vista teórico, la investigación retomó lo conceptualizado por Escudero (2009), ya que la noción que plantea supera el enfoque economicista e integra una visión humanista de la competencia, en donde se presupone que requiere la integración de los saberes por igual, y no pone énfasis en el saber hacer y hacia la resolución de problemas de carácter técnico, como los enfoques por competencias que se acercan a las propuestas conductistas.

Con el fin de complementar la noción de competencias, de la que parte la investigación, y, porque incluye la perspectiva del ser ciudadano en el mundo, en donde cada actuación individual tiene como fundamento la responsabilidad, la conceptualización de Escudero (2009) se articuló con la perspectiva de Tobón, Sánchez, Carretero y García (2006), que plantea lo siguiente: “(..) las competencias son procesos complejos de desempeño con idoneidad en determinados contextos, teniendo como base la responsabilidad" (p. 100).

\subsection{Educación basada en normas de competencia laboral: teoría del programa}

En este apartado se describe la teoría del programa Educación Basada en Normas de Competencia. Esta se instaura como el marco epistemológico que fundamenta el enfoque por competencias mediante el cual se elaboraron los planes de estudio de las especialidades técnicas que se implementan en los CTPs. Dicho texto fue escrito por Ávila y López (2001), y para la investigación se constituyó como el fundamento para el análisis comprensivo de los relatos teóricos en torno a la EBNC.

En este texto se fundamenta que, en Costa Rica, la ETP basada en el enfoque de competencias surge de las necesidades de personal calificado que posee el sector económico productivo, en el cual existen carencias crecientes de personal capacitado que se vincule eficazmente con los mercados laborales.

Para Ávila y López (2001), la planificación curricular inicia con la recuperación de las necesidades de las empresas respecto a habilidades y destrezas, con el fin de generar programas de formación que permitan a la juventud ingresar al mercado laboral. Si se parte de dicha premisa, y como en el caso de Costa Rica, donde la apertura comercial generó un incremento del sector servicios, la DETCE se dio a la tarea de crear especialidades que dieran respuesta a las necesidades del sector productivo, las cuales son objeto de estudio de esta investigación. 
Estos autores, al plantear la fundamentación epistemológica del enfoque por competencia, a saber, EBNC, inician con la conceptualización de competencia laboral, la cual cuenta con los siguientes requisitos resumidos por Camacho (2017, p. 81):

a) Se centra en el desempeño, ya que la educación juega un papel fundamental, en el que impacta las posibilidades de actuación de las personas, con la finalidad de que no se convierta en un requerimiento formal para un trabajo o una posibilidad de acumulación de conocimientos.

b) Recupera condiciones concretas del contexto y situaciones en que el desempeño es importante. Esto permite observar directamente las relaciones entre variables, los factores del contexto ante situaciones concretas, las formas de organización del trabajo y la incorporación de criterios de evaluación acordes con situaciones más complejas.

Afirman Ávila y López (2001) que este tipo de competencia está centrada en los desempeños, se encuentra intrínsecamente vinculada al saber hacer, responde a las necesidades del contexto laboral.

Estos autores afirman que las competencias laborales se integran por varias habilidades, y se traducen en la ejecución de actividades observables y pueden ser aplicadas en diferentes contextos, ya sean personales, sociales o profesionales (Ávila y López, 2001). Aspecto que puede ocasionar algún grado de confusión, porque desde la lógica de la programación de las competencias, estas están integrada por varios desempeños y no habilidades.

Los desempeños, les permite a las personas movilizar sus saberes para dar respuesta a una situación o un problema, en el cual, se demuestra que se han desarrollado las competencias necesarias, y por tanto, se es competente. En estas situaciones, en las cuales se observan los desempeños, se percibe la flexibilidad de las competencias dentro de la planificación curricular.

A pesar de definir la competencia como un conjunto de habilidades, Ávila y López (2001), se refieren al concepto de desempeño como el aspecto de la competencia que explica la lógica de los procesos de formación en los cuales se sustenta el saber hacer, es el lugar donde se integran teoría y práctica para ejecutarlo en las diversas experiencias de aprendizaje, ya sean individuales o colectivas.

Otra de las características de la competencia es la dimensión integradora según estos autores, porque la competencia se encuentra constituida por los diferentes saberes, y es más que la suma de sus partes, por tanto, cuando se da respuesta a una situación problema se 
integran los diferentes aspectos, así en el planeamiento de las actividades de aula, el profesorado debe generar situaciones que les permita dar seguimiento al nivel de desarrollo de las competencias necesarias, basados en la actuación de los desempeños y por medio de diversas prácticas evaluativas, situadas en la valoración de procesos, generación de productos y en los resultados de aprendizaje.

De estas características, según Ávila y López (2001), se derivan tres aspectos significativos relacionados con la didáctica, para que una actividad corresponda a una competencia, esta debe contener un resultado observable, entendiendo este como un producto, el cual se caracteriza por tener un valor intrínseco, ser útil para aquel que la posee y ser de un nivel superior al de las habilidades, la competencia es más compleja y más exigente.

Con respecto a la educación basada en normas de competencia laboral:

La educación basada en normas de competencia es una modalidad educativa que promueve el desarrollo integral y armónico del individuo y le capacita en todas y cada una de las competencias que le requieren una actividad productiva específica. Así, por un lado se atiende las necesidades del sujeto y por otro los requerimientos de los sectores productivos. (Ávila y López, 2001, p. 26)

Al plantear estos autores que los programas de estudio de las especialidades técnicas se definen en las empresas y de acuerdo con sus necesidades, y al revisar estos se puede constatar que promueven conocimientos teóricos prácticos, y que los referentes al saber vivir y convivir, no se encuentran definidos, por tanto, no se percibe la forma en que se promueve el desarrollo integral de la persona estudiante. Se señala que:

(...) la definición de las competencias laborales marca el principio y el fin del proceso de formación y /o capacitación y de ellos se derivan todos sus componentes: propósitos, objetivos, estrategias didácticas, procedimientos de evaluación. Por lo tanto, dichas competencias permiten identificar los resultados de aprendizaje y remiten al concepto de desempeño. (Ávila y López, 2001, p. 27)

A esta premisa se suma que la educación para el trabajo es un derecho de todas las personas que habitan Costa Rica. No obstante, una propuesta educativa que aspire a formar un ser humano integral, no puede estar centrada en responder a los requerimientos del sector productivo y solo poner énfasis en las competencias que den respuesta a una 
actividad productiva, porque, significaría reducir una propuesta educativa a las lógicas de un mercado segmentado, obviando que la diversificación de los mercados es una característica de las economías globales.

Importante resaltar que, al plantear una competencia centrada en los desempeños necesarios para hacer frente a la resolución eficaz de aspectos cotidianos o laborales, se genera un discurso que significa al ser humano de forma utilitaria, centrado en los quehaceres, que en consecuencia, restringe a este grupo de personas la posibilidad de integrar todos los saberes en una educación que promueva el desarrollo integral de la persona.

Por consiguiente, es necesario que la integralidad de los saberes sean abordados por las propuestas educativas, porque estos son requisito fundamental para formar seres humanos que puedan adaptarse a la transformación de los mercados, de lo contrario al solo contar con habilidades que respondas a una actividad productiva, afrontaran, las personas, durante su vida la posibilidad que su área de formación desaparezca como actividad productiva.

\subsection{Las prácticas evaluativas en los enfoques por competencia y la EBNC}

El tema de la evaluación por competencias es complejo, lleno de retos, y en un cambio de enfoque curricular, la evaluación se ve afectada directamente, ya que forma parte del planeamiento integral de las actividades de clase. La evaluación por competencias trata de un proceso que requiere de una actitud diferente e innovadora del personal docente, requiere de una participación muy activa de estos, y una atención más enfocada en cada estudiante (Jiménez, 2008).

El planteamiento de un programa por competencias requiere que se cambien las formas de evaluar, los criterios evaluativos, además de las formas de valorar el grado de desarrollo de las competencias por parte del estudiantado. Según Cabrerizo, Rubio y Castillo (2008):

Deben cambiar las formas de evaluar desarrollando estrategias evaluadoras acordes con la nueva realidad educativa, de acuerdo a criterios de evaluación previamente establecidos, teniendo en cuenta que lo ha de evaluarse es el grado de adquisición ${ }^{5}$ de las competencias básicas por parte del alumnado. (p. 232)

\footnotetext{
${ }^{5}$ En la investigación se utiliza grado de desarrollo de las competencias en lugar de adquisición como lo plantean los autores, ya que se parte de una noción integral de competencia, basada en un enfoque socio constructivista.
} 
Afirman, además, que en la programación curricular es necesario que se integren las prácticas evaluativas, las cuales deben lograr representar la progresión de los saberes en términos de desempeños, y lograr plantear actividades que permitan que se observen, valoren y comprueben los desempeños del estudiantado en términos del proceso de desarrollo y resultados dispuestos en productos, y que el profesorado logre dar cuenta de si se han desarrollado y en qué nivel. A estos planteamientos les suman que:

Evaluar el grado de adquisición de las competencias básicas, supone modificar a fondo la forma tradicional de evaluar del profesorado, centrada sobre todo, en comprobar la adquisición de contenidos. En esta nueva forma de desarrollar el proceso evaluador, es necesario evaluar cada uno de los componentes que constituyen las competencias básicas (contenidos, habilidades, actitudes y valores, y estrategias de aprendizaje), en un contexto y momento determinados, de forma que pueda darse una expresión (cuantitativa o cualitativa) que indique el grado de adquisición de todas y cada una de las competencias básicas hasta ese momento (nivel de desempeño), en función de los componentes de dichas competencias fijados para ser conseguidos hasta ese momento. (Castillo y Cabrerizo, 2010, p. 235)

Por tanto, es primordial que se establezcan los niveles de desempeño de la competencia a desarrollar por el estudiantado, con la finalidad de que las personas docentes puedan observar las actuaciones de las personas estudiantes, y por tanto los niveles alcanzados por cada uno de estos, tomando en cuenta contenidos, habilidades, actitudes y valores, y la resolución de problemas.

Los niveles de progresión de las competencias a lograr por el alumnado se fijan por ciclo educativo, ya sea trimestral, semestral o anual. El desarrollo de las competencias, muchas veces, necesita aportes de diversas materias o áreas disciplinares, y en este caso es necesario que el profesorado coordine las estrategias de aprendizaje.

Castillo y Cabrerizo (2010) proponen que para evaluar el grado de desarrollo de las competencias es necesario:

1. Establecer los criterios evaluativos como referente para la evaluación

2. Programar las actividades que deben realizar las personas estudiantes

3. Especificar el tipo de información que se espera proporcione cada competencia

4. Establecer la relación de cada actividad con cada competencia

5. Establecer los criterios de calificación 
Zabala y Arnau (2009) afirman que la mejor forma de valorar el desarrollo de las competencias en las personas estudiantes es por medio de situaciones - problemas, que permitan planificar actividades complejas, en las cuales se visualice y se dé seguimiento a los grados en que se han desarrollado las competencias establecidas en el programa.

En resumen Zabala y Arnau (2009) plantean que para valorar las competencias:

- $\quad$ se presenta la situación en la que se deben ejecutar estas.

- $\quad$ se valora la capacidad de análisis y comprensión respecto a la situación presentada.

- $\quad$ se reconoce la capacidad de conocimiento y selección del esquema de actuación apropiado del alumno o de la alumna.

- Se evalúa la competencia en sí, que refiere a la valoración de la respuesta ante la situación presentada, tomando en cuenta que esta actuación sea flexible y estratégica.

\section{Metodología de la investigación}

Por medio de la investigación se generaron relatos desde las perspectivas de los diferentes participantes, "...sometidos a movimientos intelectivos de naturaleza comprensiva - interpretativa, partiendo de los relatos teóricos que fueron previamente construidos." (Camacho, 2017, p. 133). Este proceso orientó la recuperación de la información necesaria en torno a la implementación de la EBNC en los CTPs.

\subsection{Enfoque}

La investigación evaluativa se desarrolló desde un enfoque cualitativo de carácter analítico interpretativo, se utilizó como método de interpretación la hermenéutica, la cual posibilitó la construcción de relatos por medio de la comprensión interpretativa. Los relatos construidos, por medio de la investigación, refieren a: los elementos teóricos, los relatos de docentes, el relato estudiantil, el de la norma y los curriculares.

La construcción de los relatos se realiza a partir de una realidad que es explicada e interpretada por las personas participantes de la investigación, las cuales construyen su perspectiva en torno al tema. Además, permite a la investigadora construir su propio relato por medio de una analítica comprensiva, en esta construcción integra su relato con los otros relatos. Dando paso al punto de convergencia entre estos, pone en común los relatos de lo social, lo político, lo económico e histórico, así como la cotidianidad de la implementación de la EBNC en su contexto pedagógico y de aula. Lo que, transcurre por el enfoque cualitativo, el cual permitió que la investigadora fuera parte de la realidad que se estudió. 
La narrativa es construida sobre los fundamentos de la hermenéutica, la cual se realizó por medio de un acto interpretativo y argumentativo contraponiendo los relatos de la investigación: teoría, práctica, currículo, discurso de las personas docentes y discurso de las personas estudiantes, “...con el fin de generar una sola discursiva sobre el tema estudiado, entendiendo está última (la discursiva), como la posibilidad de establecer relaciones entre distintas partes de los discursos o relatos $6 . "$ (Camacho, 2017, p. 135)

El análisis comprensivo se logró elaborando la narrativa desde los planteamientos de la hermenéutica, la cual como método sitúa la narración de la investigadora como el momento donde convergen el tema de investigación, los relatos y la interpretación. La comprensión interpretativa tuvo lugar en aquellos espacios o momentos en donde se logran leer, rescatar vivencias y experiencias de las personas como sujetos políticos e históricos, todo esto mediante la capacidad de situarse de la persona que interpreta.

\subsection{Unidades de análisis}

Las personas participantes de la investigación se constituyeron por un grupo de 18 docentes que laboran en las especialidades técnicas del sector comercial y de servicios en los CTPs. Además, se realizaron 4 grupos focales de un mínimo de ocho y un máximo de doce estudiantes en las instituciones educativas en donde se entrevistaron docentes, las entrevistas y grupos focales se realizaron entre el 2015 y 2016 . De cada persona entrevistada o participante de la investigación se obtuvo el consentimiento informado.

El criterio de selección de los CTPs fue implementar, al menos, dos especialidades técnicas del sector comercial y de servicios, bajo este criterio la DETCE seleccionó los CTPS en los que se realizó el trabajo de campo, posteriormente se debió contar con el aval de la dirección de la institución educativa.

El grupo de personas docentes que participó en la investigación fue seleccionado de acuerdo con los siguientes requisitos: laborar en un colegio técnico profesional del MEP e impartir clases en una de las especialidades técnicas del sector comercial y de servicios. Para lograr una comparación entre especialidades se solicitó a las instituciones educativas que se eligieran dos docentes de Ejecutivo para Centros de Servicios o Secretariado Ejecutivo y dos docentes de otra especialidad, además se estableció como criterio que las personas docentes tuvieran la disposición de realizar la entrevista y de analizar con la

\footnotetext{
${ }^{6}$ Para la investigación se entienden relato y discurso como sinónimos, comprendiendo estos como producción textual $u$ oral que se emite en torno a una interpretación de la realidad, referida a un tema.
} 
investigadora los instrumentos de evaluación y el portafolio de evidencias de las personas estudiantes.

Para la selección de los grupos focales estudiantiles, se utilizaron los siguientes criterios: se realizó un grupo focal por CTP en el que se entrevistaron personas docentes, se solicitó que el grupo estuviera conformado por mínimo 8 personas estudiantes y por un máximo de 12, y que las personas participantes cursaran clases con las personas docentes entrevistada, además de cursar undécimo año de la especialidad al momento de la investigación.

\subsection{Técnicas de recolección de información}

Por ser la investigación de corte cualitativo, las técnicas que se utilizaron se orientaron a la indagación de significantes que permitieran dar respuesta a las preguntas e interrogantes de la investigación. Se utilizaron:

Análisis documental: por medio de este se revisaron los programas de estudio de las especialidades de Ejecutivo para Centros de Servicio y Secretariado Ejecutivo, los cuales son elaborados por la Dirección de Educación Técnica y Capacidades Emprendedoras del Ministerio de Educación Pública. De estos programas se analizó la estructura de coherencia vertical y horizontal, así como la relación con el marco epistemológico y la forma en que se disponen las unidades de estudio bajo la EBNC en términos de resultados de aprendizaje y desempeños dispuestos para las personas estudiantes.Además, se revisaron los portafolios de evidencias de las personas estudiantes.

Este análisis permitió construir y analizar críticamente lo discursivo de los relatos, entendido como la comprensión de los medios a través de los cuales las personas dan sentido al mundo, con acciones significativas.

Las entrevistas cualitativas y la recuperación de los relatos: las entrevistas fueron seleccionadas para recuperar los relatos docentes, esto con el fin de analizar el contexto educativo-pedagógico y la vida cotidiana de las personas participantes, pues el hablar sobre sus experiencias permite que los sujetos las objetiven. El instrumento se validó por medio de criterio de expertos.

Los grupos focales, voces de estudiantes: esta técnica fue seleccionada con el fin de recuperar el relato colectivo de las personas estudiantes sobre sus experiencias en el aula en el proceso de enseñanza y aprendizaje basado en la EBCN y las prácticas evaluativas en el marco de este. 


\subsection{Procesamiento de análisis}

La construcción de la narrativa se realizó en dos momentos: el primero, por medio de un análisis interpretativo de textos, y el segundo, en el aula, con las historias de docentes y estudiantes, donde se construyeron los relatos en torno a la implementación de la EBNC, las nociones por competencia y las prácticas evaluativas vinculadas al enfoque.

El análisis se desarrolló por medio del método de la hermenéutica, la cual logró integrar los relatos y construir la narrativa, por medio de procesos de reflexión y de análisis crítico. Además, se analizó la interacción discursiva, llevando los relatos individuales a la narración colectiva.

\section{Resultados: análisis y discusión de la narrativa ${ }^{7}$}

Este apartado presenta las argumentaciones críticas sobre las nociones y prácticas evaluativas en la $\mathrm{EBNC}^{8}$ mediante los relatos de las personas docentes y estudiantes en torno a la noción de competencia, la implementación del enfoque y las prácticas evaluativas. Los relatos son analizados comprensivamente junto con los relatos teóricos, poniendo especial énfasis en lo planteado por Ávila y López (2001), ya que se dispone como el marco epistemológico que fundamenta la implementación de la EBNC, así el análisis crítico integra teoría y práctica.

Para el profesorado entrevistado la competencia es una habilidad o característica de las personas, la cual puede ser innata o adquirida -, además, puede ser aprendida en el aula, tiene una parte teórica y otra práctica, que le permite al estudiantado ser capaz de realizar tareas que se le asignan. Esto se ejemplifica con lo planteado en las entrevistas por la persona profesora 11: "Es una habilidad que es a veces innata $u$ otras la adquieren los muchachos en el aula, el reto del docente es poder observar cuales estudiantes ya tienen habilidades y a cuáles hay que desarrollárselas". Importante resaltar que se plantea la necesidad de que las personas docentes cuenten con la capacidad de lograr valorar el grado de desarrollo de las competencias de cada persona estudiante, mediante la utilización de una variedad importante de instrumentos evaluativos.

De este fragmento se desprende que las competencias tienen un carácter personal, porque hay estudiantes que las han desarrollado previamente o han contado con ellas desde

\footnotetext{
${ }^{7}$ Partiendo de los relatos de diferentes sujetos la narrativa la construye la investigadora, es quien le da unidad. En esta se mezclan diversas perspectivas integradas por la narradora.

8 Los extractos de las entrevistas presentados en este texto coinciden con los presentados en el documento de tesis, esto porque son representativos de lo que plantearon estudiantes y docentes.
} 
siempre, y que la tarea del docente es lograr observar cuáles estudiantes necesitan de actividades de aula para lograr desarrollarlas.

Además, en lo expresado por este profesor subyace un aspecto importante que todavía no se encuentra en las discusiones teóricas de los diversos autores que fundamentan los enfoques por competencias, sin embargo, en los programas que implementa el enfoque se ha reflexionado sobre si la competencia tiene un carácter innato o es posible desarrollarla en los espacios educativos; sobre la cual no se tienen acuerdos basados en evidencias. Por tanto, conviene dejarlo al descubierto, porque estos relatos dejan en evidencia la discusión sobre el tema, sobre todo porque implica al papel del docente en el aula y de cómo se asumen y significan al realizar los procesos de enseñanza aprendizaje desde la EBNC. Aspecto que se resume en lo que plantea la persona profesora 6 :

Una competencia es como una habilidad, puede ser aprendida o puede ser innata, por ejemplo, yo puedo observar que algunos estudiantes que tiene habilidad para tomar decisiones o para cambiar una cosa por la otra, o para analizar y para mí eso es una competencia de la persona porque ya la trae. Hay otros alumnos que hay que írselas desarrollando (persona profesora 6).

Importante destacar que en el relato docente se identifica el uso de la palabra adquiridas, es decir que a pesar de que en el fondo hay un debate de si las competencias son innatas o se desarrollan, cuando se refieren a lo que sucede en el aula, lo hacen en términos de que estas pueden ser adquiridas. En el uso de este término se puede mirar una alineación con los planteamientos de Ávila y López (2001), noción, que además, es utilizada por la escuela de pensamiento conductista laboral; de lo que se puede concluir que lo planteado teóricamente se encuentra interiorizado en los relatos de las personas docentes por medio de los planes de estudios.

Sobre el desarrollo de una competencia, la persona profesora 15 plantea, que se da: "Cuando uno tiene una competencia adquirida [lo que] significa que uno es competente o capaz de realizar unas tareas que se le asignan, es decir que los estudiantes puedan realizar lo que se les pide que realicen, aplicando los conceptos que se les ha enseñado". De esta afirmación se desprenden evidencias adicionales para confirmar que los relatos docentes se encuentran alineados, en alguna medida, con lo planteado por diferentes teóricos y por Ávila y López (2001), respecto a que es a la hora de actuar que las personas estudiantes movilizan sus saberes y resuelven las tareas o situaciones problema que se les presentan. 
Por otro lado, en los relatos docentes se percibió un error conceptual respecto a la noción de competencias, ya que, por lo general, se refieren a estas como habilidades, y al conceptualizarlas, se señalan como competencias: la toma de decisiones o la capacidad para cambiar las cosas, las cuales están ligadas al saber ser o a lo actitudinal; estos no logran visualizar la importancia de la integración entre conocimientos, procedimientos y habilidades para la vida o interpersonales, es decir los saberes planteados por Delors (1996).

Sin embargo, sí se alinean con lo planteado por Ávila y López (2001), ya que las personas docentes hacen referencia a las competencias como la capacidad de realizar una actividad por medio de habilidades cognoscitivas y procedimentales. Además, se percibe que no hacen referencia al tema de las habilidades socioafectivas, las cuales si son planteadas por los autores consultados en la investigación. Para el profesorado enseñar la dimensión relacionada con estos saberes, es utópico, y en el espacio de aula es complicado abordarlas por medio de situaciones problema. Lo cual, se puede observar en lo referido por la persona profesora 1: "Los valores respecto a una competencia vienen en el programa de estudio, pero vienen poquito, como implícitos" (persona profesora 1), de lo que se deduce que en el aula no lo fomentan.

Según plantean los diversos autores que fundamentan los enfoques por competencias estas son visibles en el aula, cuando se planifican situaciones problema y las personas estudiantes las resuelve, no obstante, la persona profesora 3 señaló:

Las competencias no se ven en la clase, sólo están en el programa de estudio, uno lo que hace es enseñar la teoría y las habilidades asociadas a la teoría. Las competencias solo directamente las pueden ver los empleadores en las prácticas profesionales, ellos pueden ver a un estudiante desempeñándose directamente en el puesto de trabajo, por eso ellos son los que las ven, nosotros vemos las habilidades que son parte de una competencia, como si muchas habilidades formaran una competencia, eso es lo que el profesor puede ver (persona profesora 3).

Esto se complementa con lo dispuesto por la persona profesora 14:

(...) se puede observar el desarrollo de una competencia con el rendimiento que da (el estudiante) con las prácticas, en realidad se nos dice que trabajamos por competencias pero seguimos trabajando igual, no hay como un verdadero plan, yo lo entendería de otra forma, es decir, cada alumno debería ir avanzando de acuerdo a sus capacidades porque hay diferentes ritmos de aprendizaje, pero acá el sistema sigue siendo igual la 
evaluación por exámenes en donde todos tienen que rendir por igual (persona profesora 14).

Derivado de lo anterior, surge una cuestión problemática para la implementación de la EBNC, ya que, si las mismas personas docentes no creen que el desarrollo de las competencias es observable en el aula, sino, que solamente se pueden visualizar por las personas en la empresa que supervisan las prácticas profesionales del estudiantado, quedaría preguntarse: ¿cómo enseñan las competencias las personas docentes?, por un lado estos comprenden que para determinar si un estudiante la ha desarrollado, debe ser visible, pero por otro no vislumbran cómo hacerla visible, ya sea por medio de actuaciones o generación de productos, en el aula. De los relatos en general sobre la noción de competencia surgen algunas interrogantes durante el análisis crítico comprensivo:

¿Cómo el profesorado elige las competencias que se fomentan o desarrollan?; esto, al parecer, queda a libertad o es generado por un proceso de deliberación consciente, o bien, la competencia es algo que se encuentra oculto y cuando se manifiesta el docente la observa y la da por desarrollada o adquirida. Si se da en esta línea, ¿sería innecesario abordarlas en el aula? O bien, ¿se encuentran los indicios de estas en las personas estudiantes y es labor del docente sacarlas a la superficie?; todas estas son preguntas que no se abordan desde la teoría. (Camacho, 2017, p.159)

Por otro lado, algunas personas docentes hicieron referencia a que el reto para ellos se hacía visible en la mediación pedagógica, en el proceso de facilitar el desarrollo de las competencias, establecer en que nivel de desempeño se encuentra cada persona estudiante y la posterior realimentación cualitativa. Cuando dichas reflexiones se entremezclan con los extractos anteriormente citados, se denota que el mismo profesorado reflexiona y se cuestiona sobre el cómo implementar la EBNC, la cual no logran comprender a profundidad, o tal vez, se podría pensar que en el ámbito teórico si lo logran comprender, sin embargo, las dudas y las problemáticas surgen a la hora de enfrentarse al proceso de enseñanza y aprendizaje en el aula, es decir, que el centro de la discusión está en cómo poner en práctica el plan de estudios.

A todo esto se suma, que docentes con más experiencia, cuentan con otro referente, el cual está centrado en su experiencia como profesores en el modelo tradicional, por tanto, al no comprender en su totalidad como implementar la EBNC bajo lo planteado por Ávila y 
López (2001), en el día a día terminan impartiendo clases como tradicionalmente se ha hecho, aspecto que también se puede observar en el extracto de la entrevista de la persona profesora 14.

Dicha respuesta fue fundamental para el análisis comprensivo sobre los relatos, porque permitió entrever y realizar una lectura sobre los imaginarios de docentes entorno a lo que significa la competencia, cómo se implementa en el aula, y finalmente, cómo se significan ellos mismo dentro del aula, responde a la pregunta: ¿Cómo se es docente en la EBNC?, porque si finalmente se realizan las mismas actividades de aula que desde el enfoque tradicional, se podría decir que para estos el enfoque no ha cambiado, o no logran percibir en qué se diferencian, ya que no logran vislumbrar el carácter integrador de la competencia y del cómo se desprenden de esta los desempeños, los cuales permiten comprender el cómo progresa el estudiantado en el desarrollo de estas, y finalmente cómo se evalúan.

Los mismos, Ávila y López (2001), plantean en su fundamento teórico las diferencias entre la Educación Técnica Tradicional y la EBNC, la primera según los autores está caracterizada porque el aprendizaje responde procesos productivos más especializados, los contenidos de los programas de estudio son teórico - académicos, el modelo educativo no necesariamente se vincula de forma sistemática ni estructura con el sector productivo, y finalmente las unidades de estudio dentro del programa son inflexibles. Luego, caracterizan la EBNC como que es una modalidad que se adapta fácilmente a las formas de organización del sector productivo, con el que se mantiene una estrecha vinculación, y de esta se desprende que los contenidos del programa se estructura en módulos basados en los sistemas normalizados, que permiten generar progresivamente los desempeños, por los cuales las personas estudiantes deben transitar.

En lo esbozado por Ávila y López (2001), se puede encontrar la respuesta a las preguntas: ¿Qué hace la persona docente? ¿Qué hace la persona estudiante? y ¿Qué hace el empleador?, así el empleador bajo la EBNC establece las normas de competencia laboral, además, establecen el perfil de entrada al ámbito laboral, lo que significa, que dan las pautas para el diseño del programa de estudios, ya que el perfil de salida concuerda con lo establecido para ingresar a los mercados laborales, así que finalmente establecen las competencias que desarrollan los grupos estudiantiles en los años que cursan la especialidad técnica. Y el grupo de personas docentes median en el aula el desarrollo de estas, por medio de la planificación de las actividades pedagógicas. 
Además, es función del profesorado asegurarse de que el grupo de estudiantes progresen gradualmente en el desarrollo de las competencias, que la persona estudiante cuando concluye el proceso de formación se logre desempeñar en su especialidad técnica de forma eficaz.

A este aspecto se suma, que desde el criterio docente, en la propuesta e implementación de la EBNC hay un énfasis en los saberes del hacer, es decir en lo procedimental, se aprenden destrezas de los temas que determinan los programas de estudio. Por tanto, se aspira a que en el espacio de aula se replique el espacio laboral, porque de esta manera el estudiantado conocerá lo suficiente y necesario para insertarse en los mercados laborales, así que en la institución educativa se reproducirían las dinámicas, lógicas, mecanismos y valores de las economías globales, y las configuraciones de las sociedades de la información. Por lo que finalmente:

Aprender competencias supone atender un asunto de utilidad, de eficacia y eficiencia, pero como el enfoque no se pone totalmente en práctica, los diferentes grupos estudiantiles no podrían situar sus aprendizajes, ya que la competencia supone saber hacer en contexto, por tanto, presentarían carencias en los espacios laborales en los que se incursionarían, conllevando el problema de que los empresarios deberían atender en las empresas estas carencias y enseñarles a estos las competencias necesarias para las actividades laborales a las que se enfrentaran las personas estudiantes. (Camacho, 2017, p.162)

Importante recordar, que desde la Política Educativa del $\mathrm{MEP}^{9}$ el centro del proceso educativo es la persona estudiante, y el estudiantado de Educación Técnica del MEP cursa una especialidad técnica con el fin de lograr generar las competencias necesarias para ingresar en los mercados laborales, por tanto, se suma al rol de las personas docentes, hacer de su aula la construcción de un espacio rico en aprendizajes, en donde cada estudiante logre progresar por los niveles de desempeño establecidos para que se pueda declarar que ha desarrollado y alcanzado el perfil de salida establecido en el plan de estudios de cada especialidad.

${ }^{9}$ La persona: centro del proceso educativo y sujeto transformador de la sociedad, aprobada en el acuerdo del Consejo Superior de Educación número 02-64-2017 del 13 de noviembre del 2017 (http://cse.go.cr/sites/default/files/documentos/folleto politica educativa.pdf) 
Todo lo expuesto anteriormente se contrasta con los relatos de los jóvenes, a estos se les preguntó si conocían qué significaba el término competencia, en un principio, la mayoría de los participantes en los grupos focales, afirmaron no saber, o señaló que refiere a cuando se compite en una carrera o se gana un premio. Posteriormente, se delimitó la pregunta a qué es una competencia dentro del contexto educativo, afirmaron, que es la capacidad o habilidad para realizar algo con eficiencia, para la resolución de problemas en los lugares laborales, y asumir la toma de decisiones en estos espacio. Las siguientes cuatro frases tomadas de los relatos o de la discursiva de los grupos estudiantiles ilustran lo mencionado: "Es como cuando a uno le piden que resuelva un problema y uno puede resolverlo" (estudiantes 1), es cuando se es capaz de lograr algo (estudiantes 1), es una capacidad que uno tiene (estudiantes 2) y es cuando uno tiene una habilidad y esa habilidad le permite hacer cosas bien" (estudiantes 4).

Estas afirmaciones permiten leer que el estudiantado participante comprende la competencia de la misma forma que el profesorado, ya que, refieren a la habilidad o capacidad para realizar algo efectivamente, para la resolución de problemas o para ejecutar una acción. De esto se deriva que la falta de elaboración de los relatos de ambos grupos y la alineación de las respuestas de estos, se encuentra vinculado a que la concepción de competencia elaborada por la DETCE permea a todos los grupos involucrados y se reproduce el discurso normativo al igual que los docentes; falta una comprensión profunda sobre los enfoques por competencias y las formas en que se realizan los proceso de enseñanza y aprendizaje dentro de estos.

A esto se le suma, que ambos, estudiantes y docentes no comprenden el carácter multidimensional de las competencias, y que en ellas se integran todos los saberes, para estos la referencia a la competencia es lograr resolver problemas que se les presenten en situaciones específicas, por lo que, esta se vuelve algo intangible, una realidad lejana, por lo que se perpetúa el aprendizaje de contenidos.

Por otro lado, el grupo de personas estudiantes que participaron en un grupo focal 3 afirmaron que una competencia: "es como cuando la profesora le dice a uno que ya adquirió los conocimientos, como cuando a uno le va bien en un examen o una práctica" (estudiantes 3). De esta noción se deriva que el discurso de las competencias que se transmite en el aula se encuentra todavía muy vinculado a las nociones de la educación técnica tradicional, en donde el énfasis está en lo que se logra, en la nota, y no en el proceso de desarrollo de estas. Además, este grupo estudiantil, introduce el tema de la realización de los exámenes y 
el énfasis en la nota, los cuales miden el aspecto cognoscitivo, en lugar de realizarse una evaluación por criterios, donde cada persona estudiante muestra su progreso integral respecto a los desempeños que conforman una competencia, aspecto que se analiza posteriormente en este mismo texto.

Otro de los aspectos que se deriva de la respuesta del grupo de estudiantes 3 , es el énfasis en la dimensión del conocimiento y su adquisición, lo que se vincula con uno de los puntos mencionados por Ávila y López (2001) cuando caracterizan las concepciones tradicionales de la educación técnica, en donde, además se hace referencia a los aspectos teóricos de una especialidad técnica y no a la integralidad de saberes que permiten hacer frente a las situaciones problema de una persona responsable con su entorno.

Los relatos de estudiantes y docentes no logran trascender la noción de que lo que se enseña es una actividad productiva específica, aunque en el relato teórico que fundamenta la EBNC, se establece que las competencias pretenden que las personas jóvenes cuenten con una formación integral, que resulta en una mejor preparación para el mundo laboral. No obstante, lo que se logra es que se enseñe y se aprenda una actividad técnica específica y que se determine el desarrollo laboral de estos jóvenes a un puesto de trabajo específico, a pesar de que la lógica de los mercados globales y neoliberales, es que se formen personas que logren desarrollar competencias que les permitan ser competitivos, flexibles e innovadores. Si el proceso educativo solamente se vincula con un aspecto específico de un puesto técnico, las personas jóvenes no podrán hacer frente a los mercados cambiantes, puesto que al no contar con este desarrollo integral no podrían acceder a los puestos del futuro, ya que solo contaran con las habilidades específicas de un puesto u oficio.

En general, a los relatos docentes y estudiantiles, se suma la incapacidad del profesorado de pensarse en el mundo, de significarse a sí mismos como sujetos en el mundo, puesto que no cuentan con las herramientas necesarias para esta reflexión, lo que es necesario para que puedan ser conscientes de su papel en el aula, y de su rol para valorar el desarrollo de las competencias. Como no logran realizar dicha reflexión, terminan siendo individuos que se definen bajo la lógica mecanicista del mercado, en donde el ser humano reproduce únicamente un papel: el del consumo, y donde se asume una identidad construida y significada desde afuera, y no una situada dentro de su contexto, que le permite dar sentido a su vida, a su papel como docente y como ser humano que transita en un mundo con una ciudadanía responsable y que por tanto, logra transmitir estas significancias a las personas jóvenes. 
Entonces, en el aula, se reproducen las lógicas de la sobrevivencia en el mundo globalizado:

(...) las destrezas prácticas enseñadas posibilitan que las personas cuenten con estructuras cognitivas para desempeñar su papel dentro de las lógicas del mercado, logrando interiorizar ese yo que consume y que le da identidad, que es lo que finalmente da sentido al ser humano. Se enseña a saber sobrevivir dentro de las economías globales. Así, el estudiantado se forma para asumir un papel específico en las sociedades postindustriales que erigen la cultura. (Camacho, 2017, p. 172)

Cuando se contrastan los relatos teóricos planteados por Ávila y López (2001), con la percepción del profesorado y de las personas estudiantes sobre el enfoque por competencias, sobresalen los criterios y opiniones de las personas docentes acerca de la EBNC, y a pesar de que los relatos docentes son múltiples, cuando estos se analizan para construir la narrativa son unitarios, las personas entrevistadas y las que participaron en los grupos focales conciben y comprenden de forma similar la competencia, a partir de esto se pueden plantear las siguientes preguntas ¿por qué se produce esta estandarización al pensar la competencia?, ¿por qué se dan estas igualdades cuando proceden de una multiplicidad? Esta unidad de las respuestas pueden provenir, por un lado, de la interiorización de lo planteado en la fundamentación teórica del enfoque, y por otro de la falta de comprensión y análisis crítico de este, en donde se repite un discurso, que carece de referentes y significancia y que está vacío, porque no permea las prácticas dentro del aula.

A continuación se presenta la respuesta de la persona profesora 1, la cual integra su percepción sobre las competencias, cómo se desarrollan y cómo se evalúan:

Una competencia es lo que se evalúa cuando ya los muchachos están haciendo la práctica en las empresas. En la competencia hay mucho que es muy personal, un par de estudiantes, uno es más extrovertido y otro más introvertido, sin embargo, tienen el mismo conocimiento, pero el extrovertido es el mejor calificado. Para mí, competencia es eso el más proactivo y más pellizcados en el trabajo (persona profesora 1).

Por un lado, este persona profesora muestra en su respuesta, que sólo logra relacionar las competencias con las habilidades interpersonales o con la dimensión socioafectiva, y es otro ejemplo de la falta de comprensión de la multidimensionalidad de la competencia; en 
donde los otros saberes no se perciben dentro de los aprendizajes necesarios a desarrollar para para hacerle frente o incorporarse a los mercados laborales.

Respecto a la evaluación por medio de prácticas evaluativas, se afirma, al igual que otras personas docentes, que estas no pueden ser evaluadas en el entorno de aula, sino solamente cuando el alumnado realiza la práctica profesional, porque para estos es el único lugar en que son observables. Pareciera que no es posible evaluarlas en el aula. Es importante preguntarse: ¿qué se evalúa en el aula entonces?

Para abordar el tema de las prácticas evaluativas, primero es importante, referirse a que todas las personas docentes entrevistadas, al igual que lo propuesto por Ávila y López (2001), plantean que las competencias son habilidades que se observan en una actuación, es decir, cuando se enfrenta una situación problema y ejecutan una serie de desempeños para lograr resolverla.

Posteriormente, se sitúa el tema de que algunas competencias, ya se encuentran dadas y otras se desarrollan en los procesos educativos, coinciden en que una competencia es una habilidad que se puede observar cuando se ejecuta algo, en el momento cuando el estudiantado se desempeña en alguna tarea o genera algún producto; además, para las personas docentes hay estudiantes que tienen unas competencias dadas y otros que las deben desarrollar, de lo que se deriva que le profesorado no comprende cómo enseñar las competencias, por lo tanto, entienden generalmente lo que son las competencias, pero al planificar las actividades didácticas de aula, no se comprende la ruta que se les debe dar ni como llegar a los resultados de aprendizaje o cómo mediar las actividades.

Luego, si se analiza a profundidad el razonamiento detrás de estas afirmaciones, de que las competencias se desarrollan y se valoran cuando se ejecutan, es que las personas docentes realizan el proceso de enseñanza y aprendizaje, enseñando primero la teoría y luego la práctica, porque en el momento en que se ejecuta es cuando se logra visualizar su desarrollo, esto, por medio de generación de productos de proceso o de resultados finales. Por tanto, concluyen que las competencias solo están en el programa de estudio y lo que se enseña son los desempeños de una tarea o actividad específica.

Luego, al platear el tema de las prácticas evaluativas, el profesorado afirmó que los criterios de desempeño dados en el programa de estudio se utilizan muy poco, porque por la normativa establecida por el MEP deben de apegarse al Reglamento de Evaluación de los Aprendizajes, por tanto, se centran en valorar contenidos en pruebas escritas y afirman que los desempeños los evalúan en el portafolio de evidencias, en forma de autoevaluación, con 
el fin de que las personas estudiantes reflexionen formativamente sobre el desarrollo de las competencias, esta interpretación se desprende de afirmaciones como las de la persona profesora 11: "El desempeño no se evalúa, solo se toman en cuenta para uno ver lo formativo, aunque los estudiantes no reciban realimentación sobre eso porque a ellos solo les importa la nota”.

De esta afirmación se desprende que al no realizar las devoluciones cualitativas o de evaluación formativa a las personas estudiantes, y al omitir la devolución del desarrollo progresivo de los desempeños, tal como, lo plantea el plan de estudios, son ellos mismos los que fomentan que la evaluación este reducida a la medición, poniendo énfasis en lo sumativo, es decir en la nota. Dejando de lado que el Reglamento de la Evaluación de los aprendizajes sustenta teóricamente la evaluación en el contexto del MEP en la complementariedad de la evaluación sumativa y formativa, poniendo énfasis en el proceso de aprendizaje y no en el producto final.

Se desprende de estos aspectos, que cuando se piensa al sujeto desde la perspectiva de que en el proceso de aprendizaje lo que importa es el producto final, en donde la asignación de una nota, dicta si se han desarrollado ciertos conocimientos, y que por tanto, se mide lo que se sabe y lo que se es, y no se realiza una evaluación para los aprendizajes completa. Lo que denota la incapacidad de las personas estudiantes para comprender cómo aprenden, qué aprenden y por qué lo aprenden, porque el énfasis solo está en el resultado final, en el producto que se genera, lo que se traduce en el ejercicio de una función social permeada por la perspectiva económica.

La EBNC plantea que la evaluación para los aprendizajes se realiza basada en la recolección de evidencias, que permiten observar los desempeños ejecutados por las personas estudiantes, los cuales, finalmente, dan cuenta del desarrollo de las competencias. Además, proponen que el profesorado debe abrir espacios para la realimentación cualitativa del desarrollo de las competencias por parte del grupo estudiantil.

Esto, además se vincula con que el Reglamento de los Aprendizajes establece una serie de componentes como procedimiento para la evaluación, estos son: pruebas escritas o de ejecución, proyecto, extraclase, trabajo cotidiano y portafolio de evidencia, y por tanto, las personas docentes justifican que solamente utilizan las pruebas escritas, porque estos componentes son contrarios a la propuesta evaluativa de la EBNC, y que, no existe coherencia entre enfoque educativo, plan de estudios, planeamiento didáctico y prácticas evaluativas. Esto se puede leer en lo que plantea la persona profesora 18: "El reglamento de 
evaluación de los aprendizajes no es coherente con las competencias, hay poca información de las pruebas de ejecución entonces es muy difícil evaluar lo que es práctico". Además, otros docentes apuntan que:

La cantidad de exámenes dependen de las unidades, es flexible, sin embargo, por trimestre tiene que haber dos, ya sean escritas o de ejecución (persona profesora 3).

El desempeño va implícito en el cotidiano. El desempeño del trabajo cotidiano también se coevalúa. El desempeño lo evalúo como proactividad (persona profesora 1).

Una competencia se evalúa por medio de la observación, el programa que da el MEP la evaluación no concuerda con el programa de competencias, a pesar de que dan la escala y dan todo, es muy difícil que yo le diga a usted, que eso se puede meter dentro de lo que es evaluación o los exámenes, porque a mi criterio eso no mide una competencia, yo lo hago observando. Lo que hago es darles la escala y que ellos mismos la completen, y si alguno me pone no lo logro, yo lo llamo y le pregunto que por qué, que dónde es que está fallando y lo trabajo (persona profesora 6).

Estas afirmaciones ponen al descubierto que para el profesorado el enfoque por competencias (EBNC) y prácticas evaluativas no concuerdan, debido a lo que se dispone en el reglamento de los aprendizajes, ya que el profesorado reduce lo reglamentado a las pruebas escritas o exámenes, por lo que no comprender el valor de las escalas de desempeño, las cuales les permiten por medio del planteamiento de las situaciones problemas observar la progresión de los desempeños del estudiantado y además valorar los productos parciales y finales que generan las y los estudiantes. Las respuestas anteriores dejan al descubierto la falta de comprensión respecto a la noción de desempeño o criterio de desempeño que tienen las personas docentes, por lo que terminan por valorar como tradicionalmente se ha hecho, por medio de exámenes, reduciendo así la evaluación a la dimensión del saber.

De las respuestas de las personas docentes respecto a las prácticas evaluativas y el énfasis en la ejecución de las pruebas escritas, se deriva que estos comprenden que no son las ideales para valorar las competencias, pero dicha disonancia la resuelven justificando, nuevamente, que en el aula es complicado valorar el desarrollo de las competencias y los resultados finales en productos, que estas, como habían afirmado antes, solamente se observan, en términos de productos generados por las personas, en los entornos laborales, porque los ambientes permiten que el o la estudiante, por medio de tareas o actividades 
integren los saberes en una actuación que permita verificar que la competencia o competencias necesarias han sido desarrolladas, por tanto, evaluar la integralidad de la competencia en clase es prácticamente imposible para estos, por lo que se centran en valorar el saber o dimensión cognitiva por medio de exámenes. Contrario a lo que plantea la teoría, la cual expone, que por medio del planeamiento de situaciones problema en el aula, es posible comprobar el desarrollo de la competencia en cada estudiante, por medio de la observación de los desempeños logrados y la valoración del producto final.

Otro aspecto, que suma a la complejidad de la ejecución de la EBNC, es que las personas docentes deben preparar al estudiantado para la prueba del técnico medio (peritazgo), donde las competencias dispuestas en el perfil de salida de los programas de estudio son valoradas, por medio de una prueba escrita nacional, que no contempla los contextos, la integración de las competencias; lo que además, discursivamente se convierte en un lugar común para justificar la realización de las pruebas escritas, ya el proceso de enseñanza y aprendizaje se reduce a preparar a las personas estudiantes para dicha prueba.

En este sentido y desde lo planteado por lbarra, Rodríguez y García (2013) es de suma importancia que en la programación por competencias se establezcan los niveles de desarrollo de cada una de las competencias por desarrollar, con su lógica de progresión y las actuaciones asociadas; con el fin de que el profesorado logre comprender la importancia de las escalas de desempeño, ya que es por medio de estas que se logra valorar los niveles alcanzados en el desarrollo de las competencias.

Ávila y López (2001) concuerdan con estos autores y proponen que para valorar los desempeños es necesario recabar evidencias sobre el grado de avance que cada persona estudiante logra, respecto a los requisitos de desempeño establecidos en los programas de estudio, sin embargo, para la personas docentes las evidencias se traducen a las notas obtenidas en las pruebas escritas, por lo que, posteriormente no cuentan con las evidencias necesarias establecer el logro de las competencias.

Con el fin de recabar los productos que dieran cuenta del desarrollo de las competencias fue que se estableció el portafolio de evidencias, como herramienta para que estudiantes identificaran los resultados de actividades realizadas como demostraciones del desarrollo de sus competencias, por esto es que dicha herramienta tiene un papel fundamental dentro de la EBNC, no obstante, la importancia del portafolio no es comprendida ni por profesores ni por estudiantes. En el proceso de investigación se 
revisaron una serie de portafolios, y algunos tenían como evidencias las pruebas escritas y rúbricas de valoración de proyectos, extra clase y trabajo cotidiano, y otros solo contaban con los resultados de las notas trimestrales; inclusive en una institución educativa se encontró que habían eliminado el uso de los portafolios porque consideraban que no aportaban al proceso de enseñanza y aprendizaje.

El grupo estudiantil afirma en sus respuestas, que ellos conocen si han desarrollado las competencias si la suma de las notas de los exámenes, del trabajo cotidiano, del concepto, el portafolio de evidencias, los extraclases y del proyecto son positivos, afirmaciones que son coherentes con lo planteado por el Reglamento de Evaluación de los Aprendizajes y lo expresado por las y docentes.

Algunos grupos de personas estudiantes afirman que las pruebas algunas veces son de ejecución, pero que la mayoría de las veces son escritas. El grupo de estudiantes 1 afirmó: "... a veces hacen de ejecución pero pocas veces, digamos a nosotros nunca nos ha tocado, eso les toca a los de sexto". De la misma forma, los estudiantes del grupo 3 plantearon: "También hacemos exámenes prácticos pocas veces, como el de la unidad de destrezas tecnológicas, que es en la computadora, pero creo que ese es el único que hacemos así, o por lo menos este año". Contrario a lo que plantea el Reglamento, porque en este se afirma que una prueba es escrita y otra de ejecución.

Las prácticas evaluativas, a criterio de del estudiantado, se encuentran centradas en las pruebas escritas. Esto se advierte en lo que plantean las personas estudiantes del grupo focal 3: "Acá nos evalúan prácticamente solo con exámenes, digamos practicamos una receta, pero al final el examen es sabérsela de memoria” (estudiantes 3). De esta afirmación se desprende que, a pesar de que en el contexto de aula se presentan situaciones problema para que las personas estudiantes resuelvan, las personas docentes posteriormente miden sus conocimientos con exámenes. Luego, las personas docentes, tal y como la afirmaron en las entrevistas, perciben que el estudiantado mantiene su mirada en la nota y no en el proceso, por lo que los procesos de desarrollo de las competencias pierden relevancia. Esta percepción tuvo como consecuencia que las personas docentes dejaran de realizar las realimentaciones y el llenado de las escalas de desempeño, consecuentemente generaron que el énfasis continuara puesto en la nota. Por ende, las personas estudiantes no comprenden la lógica de la progresión de las competencias, afirma el mismo grupo de estudiantes 3 que: "Nunca nos han dicho si hemos logrado desempeños o si somos competentes en algo" (estudiantes 3). 
Complementariamente, las personas estudiantes describen que el trabajo cotidiano es evaluado por medio de una práctica de clase y que la/ el profesor, les comunica con anticipación el día en que el trabajo en clase será evaluado. El grupo de estudiantes del grupo 3 afirmaron que ningún grupo de estudiantes comprende cómo se evalúa este trabajo y con base en qué criterios.

Las personas estudiantes perciben el proyecto y los extraclase ${ }^{10}$ como tareas que se desarrollan en la casa y se valoran por medio de rúbricas, y que en el proyecto se le asigna un alto puntaje a la creatividad. Al parecer, las personas docentes no comprenden a profundidad el potencial que, como herramientas evaluativas, tiene el proyecto, los extraclase o el trabajo cotidiano, porque en sí estos cuentan con el potencial de convertirse en prácticas de ejecución y consecuentemente en prácticas evaluativas de aula en las que se pueda observar la ejecución de las competencias. No obstante, acuden a las pruebas escritas como lugar común, sustentando su elección en que estas pruebas cuentan con mayores criterios de validez objetiva.

De las afirmaciones de las personas estudiantes se desprende que, al no comprender el profesorado de que la evaluación por competencias, está basada en el establecimiento de los niveles de desarrollo de las competencias, lo que se vincula con la progresión lógica de las actuaciones o desempeños asociados. Por tanto, es imposible que el grupo de estudiantes comprenda la importancia de estos y que piensen dichas realimentaciones como el lugar en donde se les da insumos para comprender si han desarrollado una competencia, o todavía están en proceso de hacerlo. Por consiguiente, la falta de comprensión de cómo se implementa la EBNC como una propuesta educativa genera que las personas estudiantes no logren significar su proceso de aprendizaje y además apropiarse de las competencias que han desarrollado y las que todavía deben lograr desarrollar.

Dicho aspecto se conjuga con el hecho de que las personas docentes no logran entender lo que sucede en el aula, comprenderla como dispositivo que permita que cada alumno sea el centro del proceso de enseñanza y aprendizaje, y que por tanto sea dueño de su propio proceso, y que al final esto genere que se comprenda como una persona responsable de sus actuaciones y de cómo estas tienen consecuencias en el mundo. Esto porque se carece de un proceso reflexivo de lo que se ha aprendido y cómo se ha logrado, lo que sucede porque los mismos docentes no logran comprender a profundidad cómo enseñar

\footnotetext{
10 Los extraclases son tareas cortas para realizar en la casa, se realizan dos por trimestres y tienen un valor de $5 \%$ en la nota final.
} 
las competencias, su papel en el aula y como asumir el papel de mediadores del desarrollo de estas.

Por consiguiente, al no asumir su rol no logran significarse dentro del aula como docentes, es decir, tienen una falta de comprensión sobre su propia subjetividad (noción de sujeto) como docentes de ETP y sobre lo que significa enseñar bajo la EBNC, no existe un horizonte de significación, en el sentido de que no generan por si mismos una comprensión de su lugar en el aula, en términos de Delors (1996) no saben estar en el mundo.

Consecuentemente, las personas estudiantes cuentan con las mismas carencias de reflexión, afirmación que se desliga de los relatos recuperados producto de los grupos focales, en los cuales se percibió que no se preguntan a sí mismos qué y cómo aprenden, lo que se desprende de la falta de profundidad de sus relatos, en la falta de comprensión de lo que pasa en el aula, hay una imposibilidad de generar un colectivo estudiantil con un pensamiento crítico sobre lo que viven y cómo lo viven, sobre la responsabilidad que conlleva ser y estar en el mundo, y en el contexto en que se habita.

Así:

(...) la carencia de significado de docentes y estudiantes, así como la falta de comprensión crítica sobre la EBNC y de profundidad en los relatos, devela que el plan de estudios carece de su propia propuesta de mundo, existe una falencia fundamental que radica en plasmar la necesidad del aprender a aprender como competencia fundamental para ser en el siglo XXI, tomando en cuenta que esta competencia generaría pensamiento crítico y análisis sobre el propio contexto, y cómo se vive y se es en este, es decir. Las personas tendrían la capacidad de hablar y significar su mundo, así como sus vivencias personales y laborales, más allá de sólo involucrarse en las lógicas de consumo propuestas por la globalización. (Camacho, 2017, p. 214)

Por consiguiente, si el profesorado comprendiera a profundidad la fundamentación teórica del currículo y sus implicaciones didácticas, se posibilitaría la implementación de la EBNC. No obstante, como ya se planteó, a las personas docentes se les olvida que el centro del currículo es el estudiantado, y sus intereses quedan siempre relegados, porque quienes deciden lo que sucede en el aula son las profesoras y profesores. Sus planeamientos los basan en los programas de estudio, los que a su vez se encuentran permeados por las necesidades del mercado, por tanto, el centro del currículo se desplaza a otro lugar. 
Como conclusión fundamental del análisis de los relatos en torno a la Educación basada en Normas de Competencia Laboral, se desliga que, en definitiva, el enfoque no se traslada al aula porque los planes de estudio necesitan una definición por competencias desde un enfoque más integral o sistémico, que logre permear las actividades planeadas y la mediación docente, y que las/los profesores logren interiorizar lo que significa la educación basada en un enfoque por competencias.

\section{Conclusiones}

La investigación que dio origen al presente texto surge por la inquietud que genera en la investigadora el tema de las competencias y las prácticas evaluativas asociadas a estas. Ambas son implementadas en el contexto de la EBNC, la cual se ejecuta en los Colegios Técnicos Profesionales del Ministerio de Educación Pública.

La investigación toma como punto de partida los relatos previos de las personas docentes, estos afirmaban que el Reglamento de Evaluación de los Aprendizajes (MEP, 2009) normado por el MEP, al no fundamentar y contemplar en sus rubros la especificación del enfoque por competencias, genera, en ellos, una disonancia entre la implementación del enfoque y las prácticas evaluativas, lo que tiene por consecuencia que al supeditarse al Reglamento no logren implementar en el aula lo dispuesto por la DETCE.

No obstante, mediante la construcción de la narrativa no se logra evidenciar lo planteado por el profesorado, porque el Reglamento de Evaluación de los Aprendizajes es lo suficientemente amplio para dar lugar a prácticas evaluativas alternativas e innovadoras, las cuales, son necesarias para valorar el desarrollo de las competencias de las personas jóvenes que estudian bajo la EBNC. El reglamento posibilita el planteamiento de pruebas escritas y de ejecución, la evaluación del trabajo cotidiano, la formulación de proyectos centrados en la ejecución y la recolección de las evidencias mediante el portafolio, por tanto, es de suma importancia realizar un proceso reflexivo con las personas docentes, con el fin de provocar otras prácticas evaluativas que de igual forma se enmarquen dentro del reglamento y logren valorar la progresión de las competencias.

Partiendo de este hallazgo, se plantea una nueva hipótesis de trabajo para futuras investigaciones, porque de las problemáticas encontradas por medio de los relatos, en la formulación curricular de los planes de estudio bajo la EBNC y fundamentada por Ávila y López (2001), el profesorado no encuentra diferencias fundamentales, ya que perciben que el enfoque tradicional y el de por competencias, se centran en enseñar el saber hacer, es 
decir, lo procedimental que responde a las necesidades del mercado y por tanto, a las del sector económico. O bien, que los docentes a pesar de saber que la programación curricular se realiza por competencias, no traducen esto en sus prácticas de aula y por tanto en su diseño evaluativo.

Lo anterior, se vincula que la conceptualización epistemológica de las competencias no es clara en los docenes, es decir no pueden darle significado a las competencias, por lo que carecen de una noción clara de lo que se debe planificar, mediar y evaluar.

Es preciso que las diferentes instancias involucradas en la definición de la modalidad educativa realicen un proceso reflexivo sobre el desarrollo del enfoque en todos los niveles: fundamentación teórica y práctica e implementación y resultados, con el fin de generar un enfoque comprensivo $\mathrm{y}$, por tanto, un enfoque por competencias que abarque todos los saberes, desde procesos más socioconstructivistas, que logren un equilibro entre lo que se aprende - practica en el aula y lo que se hace en la empresa - práctica profesional.

Esto, porque, desde esta perspectiva se lograría un modelo que tenga por consecuencia un impacto positivo en el desarrollo social, contribuyendo a la conformación de sociedades más equitativas y justas, con ciudadanos responsables, que comprenden su lugar en el mundo, que logran visibilizar los contextos y las identidades, las éticas y las construcciones individuales y significaciones personales situadas, y finalmente el desarrollo sostenible.

Se debe lograr superar la tendencia a la educación instrumental por una que promueva una noción de ser humano integral, que incorpore el tema de los derechos humanos, así como el desarrollo de capacidades y habilidades de pensamiento crítico y científico. Y que además posibilite la construcción de un colectivo ciudadano responsable con sus vivencias en el mundo, para hacerle frente a los retos planteados por la sociedad del conocimiento y a las problemáticas mundiales como lo son el cambio climático y la desigualdad generada por modelos económicos insostenibles, ligados a las lógicas neoliberales.

\section{Referencias}

Ávila, Gerardo, y López, Xinia. (2001). Educación basada en normas de competencia. San José, Costa Rica: INA.

Cabrerizo, Jesús., Rubio, María Julia., y Castillo, Santiago. (2008). Programación por competencias. Formación y práctica. Madrid, España: Pearson Educación, S.A. 
Castillo, Santiago y Cabrerizo, Jesús. (2010). Evaluación educativa de aprendizajes y competencias. Madrid, España: Pearson Educación, S.A.

Camacho, Silvia. (2017). Prácticas evaluativas basadas en el enfoque por competencias de varias especialidades de la educación técnica costarricense (Tesis de maestría). Universidad de Costa Rica, San José, Costa Rica.

Chomsky, Noam. (1999). Aspectos de la teoría de la sintaxis. Barcelona, España: Gedisa.

Comisión Económica para América Latina y el Caribe. (1996). Educación y conocimiento: eje de la transformación productiva con equidad (versión resumida). Recuperado de http://unesdoc.unesco.org/images/0015/001502/150253so.pdf

Comisión Económica para América Latina y el Caribe. (marzo de 1996). UNESCO. Recuperado de http://unesdoc.unesco.org/images/0015/001502/150253so.pdf

Delors, Jaques. (1996). Los cuatro pilares de la educación. Madrid, España: Santillana, S.A.

Díaz-Barriga, Ángel. (2011). Competencias en la educación. Corrientes de pensamiento e implicaciones para el currículo y el trabajo en el aula. Revista lberoamericana de Educación Superior (RIES), 2(5), 3-24.

Dirección de Educación Técnica y Capacidades Emprendedoras Ministerio de Educación Pública. (2011). Oferta Educativa de la Educación Técnica Profesocial en las modalidades de Agropecuaria, Industrial, Comercial y Servicios. San José, Costa Rica: MEP.

Escamilla, Amparo. (2009). Las competencias básicas. Claves y propuestas para su desarrollo en los centros. Barcelona, España: GRAÓ, de IRIF, S.L.

Escudero, Juan. (2009). Las competencias profesionales y la formación universitaria: posibilidades y riesgos. Revista Interuniversitaria de Pedagogía Social, (16), 65-82.

Gadamer, Hans-Georg. (2001). Antología. Salamanca, España: Ediciones Sígueme, S.A.

González, Luis Martín, Calvo, Sergio y Pérez, Gonzalo. (2006). Evaluación de los aprendizajes, aplicando la metodología por competencias. San José, Costa Rica: Organización de Estados Americanos.

González, Luis Martín, Venegas, Pedro y Madrigal, Roy. (2006). Proyecto Hemisférico. Desarrollo de competencias en la medicación Pedagógica. San José, Costa Rica: Organización de Estados Americanos.

Ibarra-Sáiz, María Soledad, Rodríguez-Gómez, Gregorio y García-Jiménez, Eduardo. (2013). Catálogo de competencias transversales a la evaluación. DevalSimWeb. Cádiz, España: Alfa III (2011)-10.

Jiménez, Jairo. (2008). Las competencias genéricas en el posgrado de la Universidad de Costa Rica (Tesis de maestría). Universidad de Costa Rica, San José, Costa Rica. 
Madriz, Luis Paulino. (1998). Análisis de factores que determinan la Oferta de especialidades en Educación Técnica en el Colegio Técnico en el Colegio Técnico Profesional de la Suiza (Tesis de Maestría). Escuela de Admisnitración Educativa, Unversidad de Costa Rica. San José, Costa Rica.

Mainieri, Aida. (2009). La formación de los profesionales de la educación técnica profesional costarricense en especialidades no tradicionales y la correspondencia con los requerimientos de los empleadores, desde la perspectiva de los actores sociales un fundamento para el cambio (Tesis para optar al grado de Doctor en Educación). Universidad de Costa Rica, San José, Costa Rica.

Maldonado, Miguel Ángel. (2006). Competencias: método y genealogía. Pedagogía y didáctica del trabajo. Bogota, Colombia: Ecoe Ediciones.

Ministerio de Educación Pública. (2009). Reglamento de Evaluación de los Aprendizajes 2009. San José, Costa Rica: MEP.

Ministerio de Educación Pública, Departamento de Educación Técnica. (2009). Especialidad: Ejecutivo para Centros de Servicios. Diseño curricular bajo el Modelo de Educación basada en Normas de Competencias. San José, Costa Rica: Consejo Superior de Educación.

Muñoz, Luis. (2012). Enfoque por competencias y mercado de trabajo. Nuevas tendencias para la educación universitaria. Actualidades Investigativas en Educación, 12(2), 130. Doi 10.15517/aie.v12i2.10283

Muñoz, Luis. (15 de Febreo de 2015). Educación y desarrollo económico en Costa Rica. Apuntes para la discusión. Observatorio de la Educación Nacional y Regional Recuperado de http://observatorio.inie.ucr.ac.cr/

Organización para la Cooperación y el Desarrollo Económicos. (27 de noviembre de 2015). Definition and Selection of Competencies (DeSeCo). Recuperado de http://www.deseco.admin.ch/bfs/deseco/en/index/03/02.parsys.78532.downloadList.9 4248.DownloadFile.tmp/2005.dscexecutivesummary.sp.pdf

Programa Estado de La Nación. (2010). Decimosexto Informe Estado de la Nación y Desarrollo Humano Sostenible. San José, Costa Rica: Programa Estado de la Nación.

Puiggrós, Adriana. y Gagliano, Rafael. (2004). La fábrica del conocimiento. Los saberes socialmente productivos en América Latina. Rosario, Argentina: Homo Sapiens.

Ricoeur, Paul. (2003). I Tiempo y Narración. Coyoacán, México: Siglo Veintiuno Editores, S.A.

Ricoeur, Paul. (2003). II Tiempo y Narración. Coyoacán, México: Siglo Veintiuno editores, S.A.

Ricoeur, Paul. (2005). Caminos del Reconocimiento. Madrid, España: Editorial Trotta, S.A. 
Rifkin, Jeremy. (1996). El fin del trabajo: nuevas tecnologías contra puestos de trabajo: el nacimiento de una nueva era. Barcelona, España: Paidós.

Tobón, Sergio. (2006). Competencias en la Educación Superior. Bogotá, Colombia: 2006.

Tobón, Sergio. (2009). Formación basada en competencias. Pensamiento complejo, diseño curricular y didáctico. Bogotá, Colombia: Ecoe Ediciones.

Tobón, Sergio., Sánchez, Antonio., Carretero, Miguel Ángel. y García, Juan Antonio. (2006). Competencias, calidad y educación superior. Bogotá, Colombia: Cooperativa Editorial Magisterio.

Organización de las Nacionaes Unidas para la Educación, la Ciencia y la Cultura (2015). Replantear la educación. ¿Hacia un bien común mundial? Paris, Francia: UNESCO.

Zabala, Antoni., y Arnau, Laia. (2009). Cómo aprender y enseñar competencias. Barcelona, España: GRAÓ, de IRIF, S.L. 
Revista indizada en

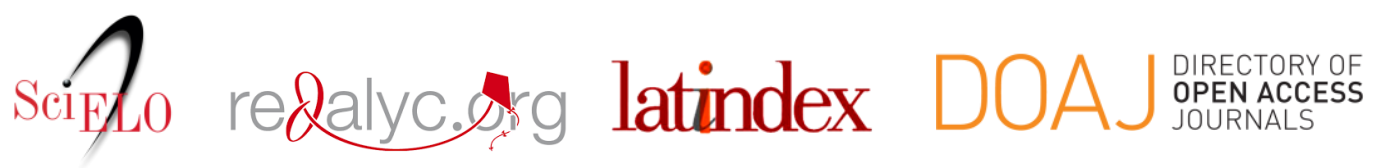

Distribuida en las bases de datos:

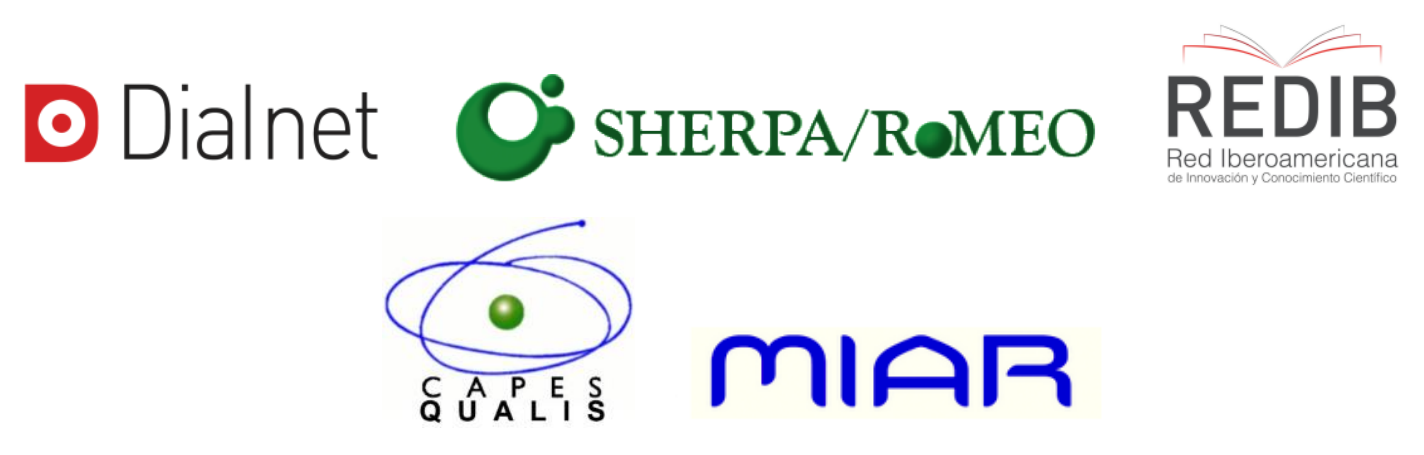

